\title{
The Design Method of Modal Test Supporting System
}

\author{
Daqian Zhang ${ }^{1, a^{*}}$, Zhengyang $\mathrm{Li}^{1, \mathrm{~b}}$, Jinliang Zhang ${ }^{1, \mathrm{c}}$ and Qingchun Sun ${ }^{1, \mathrm{~d}}$ \\ ${ }^{1}$ Key Laboratory of Liaoning Province for Composite Structural Analysis of Aerocraft and \\ Simulation, Shenyang Aerospace University ,Shenyang 110136, China. \\ azhangdaqian65@163.com, ' Izy0973@sina.cn, ${ }^{\mathrm{c}} 251836736 @ q q . c o m$, \\ dsunqingchunzhi@163.com.
}

\section{Keywords: Modal test; Supporting system; Air spring; Stiffness; Added mass}

Abstract. Modal test is one of the basic works of studying on dynamic characteristics of aircraft. The ideal state is to make the specimen in the "free-free" state when doing modal test. In actual, specimen is supported by an elastic supporting system, the stiffness, added mass and supporting position of the supporting system will affect the rigid-body modal frequency of the system directly. In this paper, we took a certain aerospace products as an example and used ANSA, NASTRAN software, studied on the influence of stiffness, added mass and supporting position of the supporting system on modal test results, and put forward the design method of modal test supporting system.

\section{Introduction}

According to statistics, about $40 \%$ major accidents of all kinds of machinery and equipment are due to vibration problems[1]. Understanding the vibration characteristics of aircrafts is the precondition of effective control of harmful vibration. The modal test is the most direct and effective means to identify vibration characteristics. We can identify dynamic parameters of products such as natural frequency, vibration mode and damping factor accurately through modal test. Therefore, the modal test is indispensable in the process of product development. But the study of influences on test results caused by different parameters of supporting system is rare in domestic and foreign literature at present. In this paper, taking a certain aerospace products as an example and using the finite element method, we studied the influence of parameters of the supporting system on modal test results and summed up the matters needed to attention in supporting system design process.

\section{Supporting Method in Aircraft Modal Test}

In order to simulate the "free-free" flying state in the aircraft modal test, it usually requires[2]:

(1)Supporting position as few as possible and the specimen is placed in the first-order elastic modal node as far as possible.

(2)Supporting stiffness as low as possible and to ensure that the rigid-body modal frequency of test system is less than $1 / 5$ of the specimen's first-order elastic modal frequency.

(3)Added mass as small as possible, had better not.

To satisfy the above requirements, the actual supporting system is as follows:

a. Air spring supporting[3]: It can adjust the supporting system's bearing capacity according to the quality and size of different specimens at anytime and used widely;

b. Steel spring-wire rope supporting: Used for large aircraft that the quality reach to one hundred tons and the diameter is 3 meters, it is the first selection of modal test supporting system of large launch vehicle;

c. Hydro-pneumatic spring supporting: It has a strong supporting capacity can be used for large bundle vehicle with the quality is as high as hundreds tons and the diameter is more than 3 meters;

The choice of supporting method is mainly depends on the structure, size and quality of the test configuration and special requirements in the modal test[4]. This paper is aimed at studying the influence of the stiffness and added mass of air spring supporting system on the modal test of 22 tons air vehicles by establishing a finite element model. 


\section{The Influence of the Stiffness and Added Mass of Supporting System on Rigid-body Modes}

In theory, analyzing the influence of supporting stiffness and added mass on rigid-body modes, could consult the natural frequency equation of single-degree of freedom system without damping(Eq. 1):

$$
f=\frac{1}{2 \pi} \sqrt{\frac{k}{m}} .
$$

In actual, using air spring in larger aircraft modal test, it usually has added mass and the supporting stiffness cannot be infinite adjusted, so it is necessary for practical problems to quantitative analysis.

\section{The Establishment of the Finite Element Simulation Model}

Using two air spring to support the aircraft products at first(as shown in Fig. 1), the basic data of the preliminary analysis is shown in Table 1.

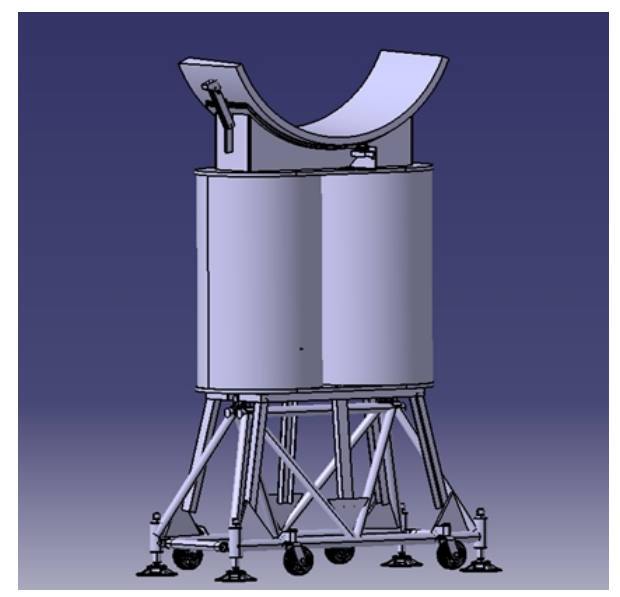

Table 1 Basic parameters of the air spring and the installation location

\begin{tabular}{|c|c|c|}
\hline $\begin{array}{c}\text { name } \\
\text { parameter }\end{array}$ & $\begin{array}{c}\text { The former air } \\
\text { spring }\end{array}$ & $\begin{array}{c}\text { The latter air } \\
\text { spring }\end{array}$ \\
\hline Quality[kg] & 8000 & 9000 \\
\hline Stiffness[KN/m] & 70 & 81 \\
\hline Coordinates[m] & 8.6 & 14 \\
\hline
\end{tabular}

Figure 1 Air spring

For the specimen, according to its structural composition and the loading mode to simplify, using ANSA, NASTRAN software, setting up the beam-shell finite element model of simulation analysis(as shown in Fig. 2), The basic parameters are shown in Table 2.

Table 2 The specimen and the basic parameters of the finite element model

\begin{tabular}{|c|c|c|c|}
\hline Parameter & Specimen & Parameter & $\begin{array}{c}\text { The finite } \\
\text { element model }\end{array}$ \\
\hline Quality[kg] & 17000 & Number of beam element & 1210 \\
\hline Diameter[m] & 12.0 & Number of shell element & 600 \\
\hline Length[m] & 15.0 & Number of quality element & 610 \\
\hline
\end{tabular}

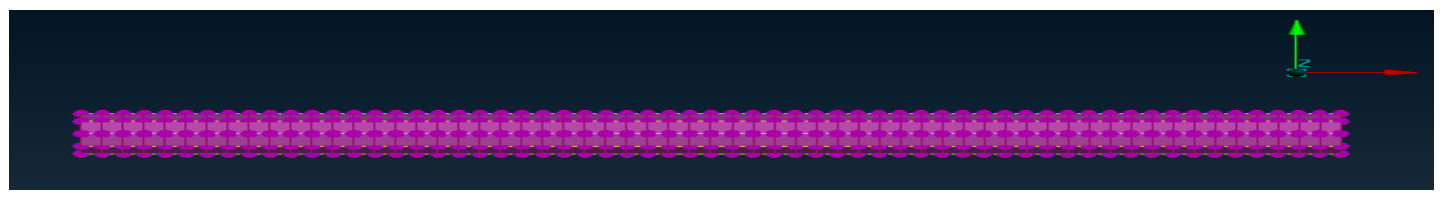

Figure 2 Simplified model

By the modal analysis of the "free-free" state, obtaining the first-order elastic frequency and vibration mode of the specimen(as shown in Fig. 3). 


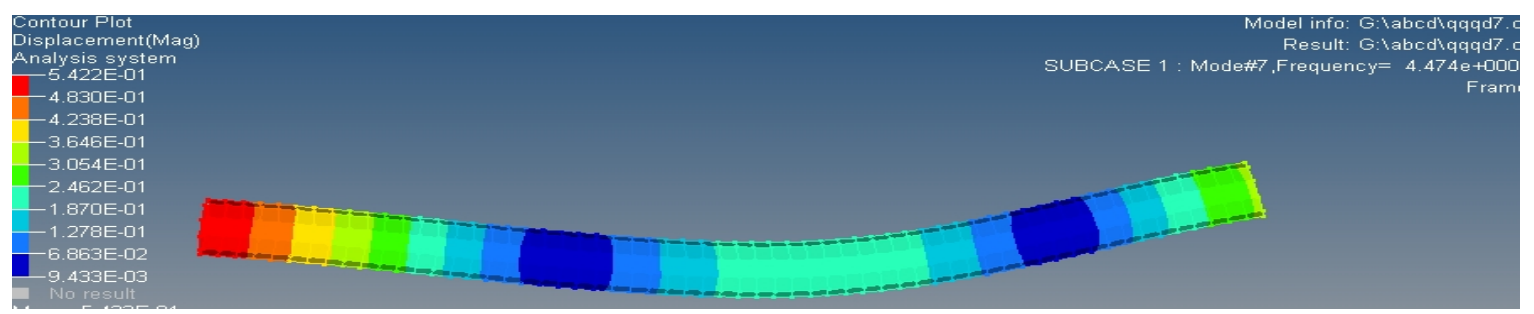

Figure 3 The first-order elastic vibration mode $(4.47 \mathrm{~Hz})$

\section{The Influence of the Supporting Stiffness}

Studied on the influence of variation of the spring stiffness on the first-order elastic mode, where the air spring in the initial designed position, both ends of the limit position, middle and right limit position, the results are shown in Table 3 and Table 4.

Table 3 The influence of the initial designed position of the air spring on the variation of the supporting stiffness

\begin{tabular}{|c|c|c|c|c|c|c|c|c|c|c|}
\hline \multirow{2}{*}{ Stiffness[KN/m] } & $\begin{array}{c}\text { The former air } \\
\text { spring }\end{array}$ & 70 & 70 & 70 & 70 & 70 & 200 & $2 \mathrm{e} 3$ & $2 \mathrm{e} 4$ & $2 \mathrm{e} 5$ \\
\cline { 2 - 10 } & $\begin{array}{c}\text { The latter air } \\
\text { spring }\end{array}$ & 40 & 100 & $2 \mathrm{e} 3$ & $2 \mathrm{e} 5$ & $2 \mathrm{e} 6$ & 81 & 81 & 81 & 81 \\
\hline \multicolumn{2}{|c|}{ The first-order elastic modal[Hz] } & 4.5 & 4.5 & 4.5 & 4.5 & 4.5 & 4.5 & 4.6 & 4.6 & 4.6 \\
\hline
\end{tabular}

By the calculation results, there is no effect on the first-order frequency when the latter air spring's stiffness changed, where the air spring in the initial designed position, the reason is obvious that the latter air spring is located near by the first-order modal node. Relative to the latter spring, the former spring is more sensitive to the first-order frequency, because of the position of the former spring is not on the node.

Table 4 The influence of the limit position of the air spring on the variation of the supporting stiffness

\begin{tabular}{|c|c|c|c|c|c|c|c|}
\hline \multirow{2}{*}{ Coordinates[m] } & The former air spring & 0.25 & 0.25 & 0.25 & 7.50 & 7.50 & 7.50 \\
\cline { 2 - 8 } & The latter air spring & 14.75 & 14.75 & 14.75 & 14.75 & 14.75 & 14.75 \\
\hline \multirow{2}{*}{ Stiffness[KN/m] } & The former air spring & 56.0 & 2.80 & 1120 & 96 & 4.80 & 1920 \\
\cline { 2 - 8 } & The latter air spring & 91.0 & 4.55 & 1820 & 52 & 2.60 & 1040 \\
\hline \multicolumn{2}{|c|}{ The first-order elastic modal[Hz] } & 4.45 & 4.48 & 4.88 & 4.50 & 4.48 & 4.63 \\
\hline
\end{tabular}

The first-order frequency $(4.48 \mathrm{~Hz})$ is close to the first-order frequency of the "free-free" state $(4.47 \mathrm{~Hz})$ when stiffness coefficient is smaller, where the air spring on both ends of the limit position. This is consistent with the theoretical analysis results. The first-order frequency reach to $4.88 \mathrm{~Hz}$ when the stiffness coefficient is larger, it increases by $9.2 \%$ than the "free-free" state. The influence is conspicuous. The first-order frequency $(4.48 \mathrm{~Hz})$ did not changed, still closed to the first-order frequency $(4.47 \mathrm{~Hz})$ of the "free-free" state when stiffness coefficient is smaller, where the air spring is on middle and right limit position. The first-order frequency reach to $4.63 \mathrm{~Hz}$ when the stiffness coefficient is larger, it increases by $3.6 \%$ than the "free-free" state.

\section{The Influence of Added Mass}

Studied on the influence of the added mass on the first-order elastic mode, where the air spring on the initial designed position, both ends of the limit position, middle and right limit position, results are shown in Table 5. 
Table 5 The influence of the added mass of the air spring

\begin{tabular}{|c|c|c|c|c|c|c|c|c|c|c|c|}
\hline \multirow{2}{*}{$\begin{array}{c}\text { Coordinates } \\
{[\mathrm{m}]}\end{array}$} & $\begin{array}{c}\text { The } \\
\text { former } \\
\text { spring }\end{array}$ & 8.6 & 8.6 & 8.6 & 8.6 & 0.25 & 0.25 & 0.25 & 7.50 & 7.50 & 7.50 \\
\cline { 2 - 11 } & $\begin{array}{c}\text { The } \\
\text { latter } \\
\text { spring }\end{array}$ & 14.0 & 14.0 & 14.0 & 14.0 & 14.8 & 14.8 & 14.8 & 14.8 & 14.8 & 14.7 \\
\hline $\begin{array}{c}\text { The } \\
\text { former } \\
\text { spring }\end{array}$ & 10 & 50 & 100 & 200 & 35 & 350 & 3500 & 35 & 350 & 3500 \\
$\begin{array}{c}\text { Added } \\
\text { mass[kg] } \\
\text { latter } \\
\text { spring }\end{array}$ & 10 & 50 & 100 & 200 & 35 & 350 & 3500 & 35 & 350 & 3500 \\
\hline $\begin{array}{c}\text { The first-order elastic } \\
\text { modal[Hz] }\end{array}$ & 4.48 & 4.48 & 4.48 & 4.47 & 4.51 & 4.21 & 3.12 & 4.49 & 4.33 & 2.70 \\
\hline
\end{tabular}

According to the calculation results, added mass has little impact on the first-order elastic frequency of air spring when the air spring is in the initial designed position and the added mass weighs less than $200 \mathrm{~kg}$. When the air spring is on both ends of the limit position, the first-order frequency decreases gradually along with the increasing quality. When it attains the same frequency with the first-order frequency of the "free-free" state, it'll offset the increased frequency due to the increasing of supporting spring. After this the first-order elastic frequency continues to decrease with the increasing of the added mass. The first-order frequency reaches to $3.12 \mathrm{~Hz}$ when added mass is $3500 \mathrm{~kg}$, this reflects a great influence; it would be closer to the frequency of the "free-free" state if the added mass is small (such as $50 \mathrm{~kg}-100 \mathrm{~kg}$ ); when the added mass is $3500 \mathrm{~kg}$, it reaches to $2.70 \mathrm{~Hz}$ which is reduced by $40 \%$ than the "free-free" state frequency $(4.47 \mathrm{~Hz})$, and that is a huge effect that we can't ignore.

\section{Conclusion}

Based on above analysis, the following factors must be taken into consideration when using air spring to design modal test supporting system:

(1)The supporting position of air spring on aircraft is the main factor of affecting the rigid-body mode of the supporting system. The change of spring stiffness would affect the frequency of rigid-body mode directly, if supporting on inappropriate position. It could lead to the coupling of both rigid-body modal frequency and low-order elastic modal frequency, cause the inaccurate test results. When the supporting position located near by the low-order elastic modal node, even if the stiffness changed bigger, it would not cause a great impact on low-order elastic modal frequency.

(2)It is a little influence of supporting stiffness on rigid-body modal of the supporting system.

(3)Lots of analysis and calculation show that lower added mass not only does not change the whole structural modal frequency and vibration mode, but also has certain quits effect to higher frequency of system constraint caused by, which will make the results closer to the "free-free" state.

\section{References}

[1] Dihua Guan, The Technology of Modal Analysis, Bei Jing: Tsinghua University Press, 1996.(In Chinese)

[2] Qin Huang, Tong Wang, Yaoqing Zhang, Jiangsu Aviation, 2009; (S1): 41-43. (In Chinese)

[3] Zhuang Qi, Fu Li, Yuanhua Huang, China Railway Science, 2013, 34(3): 79-86.(In Chinese)

[4] Haichang Yu, Journal of Astronautics, 1993; (S1): 69-75. (In Chinese) 